\title{
STUDY ON PREVALENCE OF PULMONARY TUBERCULOSIS IN DIABETES MELLITUS
}

\author{
Beenaboina Venkata Ramana Murthy', Mugannagari Maheswara Reddy², Varikuti Aparna ${ }^{3}$, N. Gopichand ${ }^{4}$, Y. Gangadhar 5
}

${ }^{1}$ Assistant Professor, Department of General Medicine, ACSR Govt. Medical College, Nellore, Andhra Pradesh.

${ }^{2}$ Associate Professor, Department of General Medicine, ACSR Govt. Medical College, Nellore, Andhra Pradesh.

${ }^{3}$ Assistant Professor, Department of Pulmonary Medicine, ACSR Govt. Medical College, Nellore, Andhra Pradesh.

${ }^{4}$ Associate Professor, Department of Pulmonary Medicine, ACSR Govt. Medical College, Nellore, Andhra Pradesh.

${ }_{5}^{5}$ Assistant Professor, Department of General Medicine, ACSR Govt. Medical College, Nellore, Andhra Pradesh.

\section{ABSTRACT}

\section{AIM}

To screen diabetic patients for pulmonary tuberculosis and find out the prevalence of tuberculosis in Diabetic patients, and to correlate the smoking habits with reference to prevalence of tuberculosis in diabetic and non-diabetic population.

\section{BACKGROUND}

Prevalence of diabetes mellitus and pulmonary tuberculosis is increasing drastically in developing countries, particularly in India. In the present study, an attempt has been made to find an association of the pulmonary tuberculosis and diabetes mellitus type 2 .

\section{MATERIAL METHODS}

This study was carried out on 500 patients of type 2 diabetes mellitus confirmed by clinical and laboratory assessment obtained from Outpatient Department of Medicine from GGH Nellore. The control group for study consists of 100 patients with pulmonary tuberculosis alone and was obtained randomly from tuberculosis clinic ACSR GMC, GGH Nellore. Out of 500 subjects 56 patients [TB DM] group were found to be suffering from also pulmonary tuberculosis; 56 age matched patients suffering from tuberculosis alone and non-diabetics [NON DM-TB] group selected randomly were compared with diabetic TB group.

\section{RESULTS}

In the present study, the prevalence of pulmonary tuberculosis in diabetics is $11.2 . \%$ with male predominance of above 40 years age group with most patients having fever as main complaint and haemoptysis as least complaint.

\section{CONCLUSION}

It can be concluded that there is increased susceptibility of tuberculosis in diabetic smoker and sputum positivity, more in diabetics than non-diabetics with more number of zones involved bilaterally in diabetics.

\section{KEYWORDS}

Diabetes Mellitus, Pulmonary Tuberculosis, Control Group.

HOW TO CITE THIS ARTICLE: Beenaboina Venkata Ramana Murthy, Mugannagari Maheswara Reddy, Varikuti Aparna,

N. Gopichand, Y. Gangadhar. "Study on Prevalence of Pulmonary Tuberculosis in Diabetes Mellitus." Journal of Evolution of Medical and Dental Sciences 2015; Vol. 4, Issue 95, November 26; Page: 16048-16051, DOI: 10.14260/jemds/2015/2343.

\section{INTRODUCTION}

There are approximately 41 million prevalent cases of DM in India and as per the International Diabetes Federation (IDF) estimates by 2025 this will rise to about 70 million, the largest number for any country. ${ }^{1}$ As well as nationally predicted rises in DM rates, regional studies have also shown increasing rates of disease, with the largest reported increases in low and middle income countries occurring amongst urban population. ${ }^{2}$ Surveys conducted in Chennai, India in 1989 and subsequently in 1995 showed a 40 per cent rise in the prevalence of diabetes over this period. ${ }^{3}$

Financial or Other, Competing Interest: None.

Submission 06-11-2015, Peer Review 07-11-2015,

Acceptance 18-11-2015, Published 25-11-2015.

Corresponding Author:

Beenaboina Venkata Ramana Murthy,

ACSR Govt. Medical College,

Flat No. 105, DSR Square,

Harnathpuram $5^{\text {th }}$ Lane,

Nellore, Andhra Pradesh.

E-mail: drmurthy26@gmail.com

DOI: $10.14260 /$ jemds/2015/2343.
One-fifth of the global TB incidence is from newly diagnosed cases within India; approximately 2 million people acquire TB yearly. Around 45 percent of these incident cases will be infectious to others, further increasing the high TB disease rates. ${ }^{4}$ Estimated that annually around 31,000 people in India die from TB. The recent WHO report indicates that the prevalence of tuberculosis in India is 283 per 100,000 population with approximately 2.8 percent of prevalent cases being problematic Multidrug Resistant (MDR) TB. ${ }^{5}$ Reports on the association between DM and TB are found as far back as 1000 A.D. when Avicenna noted that "Phthisis," (A Greek term for tuberculosis), often complicated diabetes and that the presence of diabetes resulted in an increased risk of developing TB. ${ }^{6}$ However, recently it has gone unmentioned in many global TB guidelines and in the most recent national guidelines has only been mentioned as something needing more research.5,7

A study carried out at the regional Institute of medical sciences, Imphal found the prevalence of pulmonary tuberculosis in people with diabetes to be 27 percent by radiological diagnosis and six percent by sputum positivity. ${ }^{8}$ 
In a study in Mumbai, tuberculosis was found to be the most commonly occurring concomitant illness in diabetics with 5.9 percent of the individuals in a cohort of over 8000 being co-morbidly affected. ${ }^{9}$ A meta-analysis demonstrated that having diabetes was associated with overall risk (Relative Risk) of 3.11 percent for contacting tuberculosis. ${ }^{10} \mathrm{~A}$ systematic review reporting on the association found 9 studies in which diabetes was estimated to increase risk of infection from 1.5 to 7.8 fold.11 Stevenson et al.,11 estimated the population. ${ }^{12}$ attributable risk (PAR), for tuberculosis from diabetes in India. They calculated that diabetes could account for approximately 14.8 percent of sputum positive cases. ${ }^{12}$ Engel Bach. ${ }^{13}$ and Nichols. ${ }^{14}$ posited that not only could having diabetes increase an individual's likelihood of developing tuberculosis, but that having TB could lead to the presentation of diabetes.

Studies have also shown both a high prevalence of diabetes and of impaired glucose tolerance (IGT) in patients with tuberculosis. ${ }^{15}$ A study carried out in Texas border population found that Multi-Drug Resistant TB (MDR-TB), was associated with DM with an odds ratio of 2.127, while other studies show no increased association between DM and MDRTB. ${ }^{16,17}$ However, in India evaluations of the category I treatment regimen (Not recommended for all smear positive cases) of the Revised National Tuberculosis Control Programme (RNTCP) have suggested that it is appropriate for people with concomitant diabetes. ${ }^{18,19}$ The increasing TB morbidity among diabetics has strongly been substantiated by studies of the incidence of correlation.

\section{MATERIAL AND METHOD}

This study was carried out on 500 patients of type 2 diabetes mellitus confirmed by clinical and laboratory assessment obtained from Outpatient Department of Department of Medicine from GGH Nellore. The control group for study consists of 100 patients with pulmonary tuberculosis alone and was obtained randomly from tuberculosis clinic GGH, Nellore. Prevalence was found to be 56 cases of tuberculosis among the five hundred diabetic patients. Hundred cases of patients with tuberculosis alone and without diabetes were taken as controls. All patients in this study as well as control group underwent full clinical evaluation clinical history and physical examination. Findings were recorded with particular attention to age, sex, BMI, symptoms and clinical features of tuberculosis.

Symptoms: Of duration two weeks to six months, cases underwent the investigations for confirming the diagnosis of tuberculosis.

Cough with expectoration, Fever, Loss of weight, Loss of appetite, Night sweats, Haemoptysis, Breathlessness, Chest pain, others.

PHYSICAL EXAMINATION: All patients with established diabetes underwent thorough physical examination, both general and systemic examination.

\section{LAB INVESTIGATIONS:}

Blood: Total WBC Count, Differential Count, Erythrocyte Sedimentation Rate, Haemoglobin.
Blood Sugar: Fasting (Overnight) and Postprandial. Blood-urea, Serum-Creatinine, Fasting Lipid Profile.

Urine: Albumin, Sugar and Deposits.

\section{Mantoux:}

PPD RT 23 of 1 Tuberculin Unit was used.

\section{Chest X-ray:}

Mass Miniature Radiography/Large x-ray

Sputum for Acid Fast Bacilli:

Sample A and Sample B

\section{OTHERS: CT Chest}

$\mathrm{X}$-ray chest radiological lesions were analysed by number of zones involved, nature of lesions like infiltration, consolidation, fibrosis, cavity and consolidation etc.

STATISTICAL ANALYSIS: Data's were entered in a Microsoft excel computers read sheet and analysed by using WHO epidemiological information package.

SUGGESTIONS: It is worth remembering that early diagnosis of this combination of DM and TB is not that easy.

When a combination of DM and TB is diagnosed, the TB disease is already in advance stage that it makes management more difficult, and clinical outcome is poor. From this study the following suggestions were made. The only way to recognize this dreadful combination is:

1. X -ray Examination.

a. Once in a year, or

b. With excess weight loss.

2. X -ray with sputum AFB examination.

a. For patients with cough with expectoration more than two weeks.

\section{RESULTS}

The study group comprised of 500 subjects who had established diabetes mellitus taking treatment as patients in ACSR Govt. Medical College. Out of 500 subjects 56 patients [TB-DM] group were found to be suffering from also pulmonary tuberculosis; 56 age matched patients suffering from tuberculosis alone and non-diabetics [Non DM-TB] selected randomly were compared with diabetic TB group. In the present study, the prevalence of pulmonary tuberculosis in diabetics is $11.2 . \%$ with male predominance of above 40 years age group with most patients having fever as main complaint and haemoptysis as least complaint.

\section{DISCUSSION}

It was found that there is increased susceptibility of tuberculosis in diabetic smoker and sputum positivity more in diabetics than non-diabetics with more number of zones involved bilaterally in diabetics. Infiltrations with cavity are common lesions in both groups.

\begin{tabular}{|c|c|c|}
\hline Groups & $\begin{array}{c}\text { Sputum AFB } \\
\text { Positive }\end{array}$ & $\begin{array}{c}\text { Sputum AFB } \\
\text { Negative }\end{array}$ \\
\hline DM-TB Group & $55.4 \%$ & $44.6 \%$ \\
\hline $\begin{array}{c}\text { Non DM-TB } \\
\text { Group }\end{array}$ & $\mathbf{5 7 . 1 \%}$ & $42.9 \%$ \\
\hline
\end{tabular}

Table 1: Depicting Occurrence of Sputum AFB Positivity among TB-DM and Non DM-TB Group 


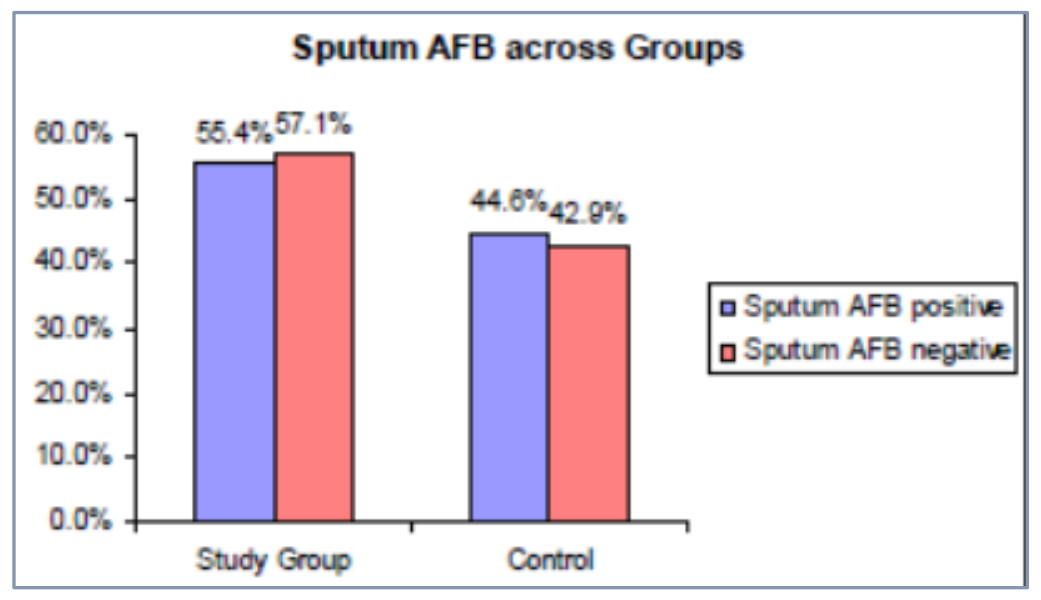

Fig. 1: AFB Positive among TB-DM and Non DM-TB

1. This matches a study in Nijmegen, with higher sputum positivity and persistence after treatment owing to the initial higher bacterial load.

\begin{tabular}{|c|c|c|c|c|}
\hline \multirow{2}{*}{$\begin{array}{c}\text { Smoking among } \\
\text { Males }\end{array}$} & \multicolumn{2}{|c|}{ DM-TB GROUP } & \multicolumn{2}{c|}{ NON DM-TB GROUP } \\
\cline { 2 - 5 } & No. & $\mathbf{\%}$ & No. & $\%$ \\
\hline Yes & 33 & $58.9 \%$ & 31 & $55.4 \%$ \\
\hline No & 23 & $41.1 \%$ & 25 & $44.6 \%$ \\
\hline \multicolumn{4}{r}{ Table 2 Smoking Habits among Males } \\
\hline
\end{tabular}

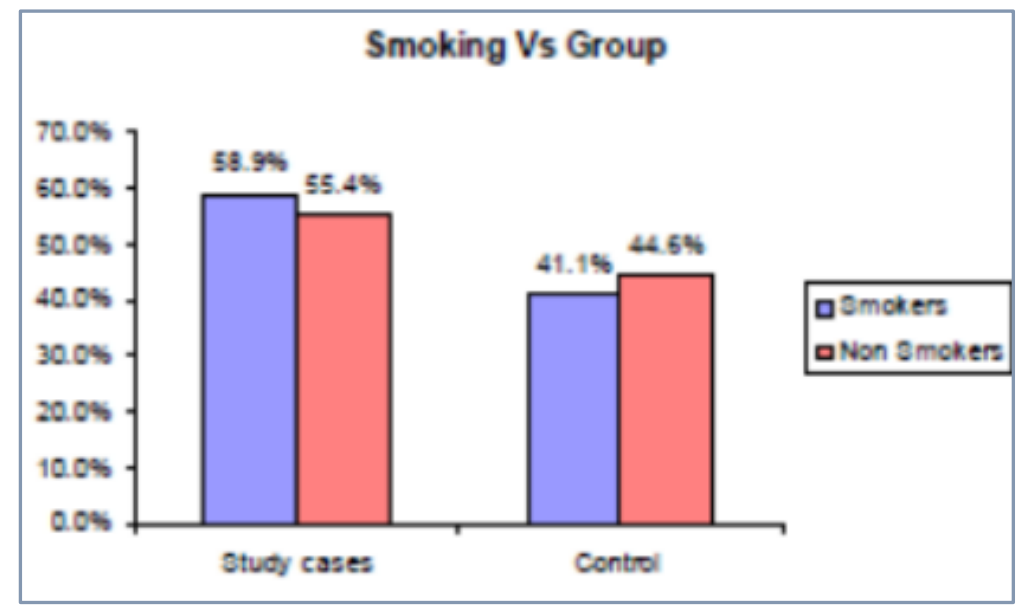

Fig. 2: Smoking in DM-TB, Non DM-TB Groups

Diabetes adds to the increased susceptibility for TB among smokers than non-smokers and non DM group.

In the study group, $58.9 \%$ were smokers and in control group $41.1 \%$ were smokers. Though there was no statistical significant correlation between DM and non DM-TB, diabetes adds to the increased susceptibility for TB among smokers than non-smokers and non DM group.

The female and male sex ratio of pulmonary tuberculosis in diabetics is:

M: $\mathrm{F}=1.67$ for Study Group and

$\mathrm{M}: \mathrm{F}=3.31$ for Control Group.

Tripathy et al., [1984] found the male:female ratio of 4:1 in patients having pulmonary tuberculosis with diabetes. It is made out that males are more susceptible than females for pulmonary tuberculosis associated with diabetes. ICMR [Anon 1958] conducted a national survey and presented its salient findings.
Age group distribution of patients suffering from PT and diabetes show a majority (82.1\%) belongs to more than 40 years of age control group $62.5 \%$.

In comparison, the control group show a more or less uniform distribution of patients in age groups between 30 to 70 years. Even then there was no statistical correlation to suggest that diabetes produces more TB lesions in the elderly population. $(\mathrm{p}=0.29)$

Majority of patients in study group presented with fever (53.65\%), chest pain (5.42\%), and loss of appetite $(23.2 \%)$, weight loss $(23.2 \%)$, and haemoptysis $(32.1 \%)$. In the control group (75\%) had fever, $0 \%$ had chest pain, and loss of appetite was seen in $30.4 \%$. Weight loss in $21.4 \%$ and haemoptysis in $7.1 \%$. The symptom complex as per the study in both group was found to be similar and there is no statistical correlation between presence or absence of diabetes influencing the complaints of the patients. This was similar to a study conducted in Regional Institute of Medical sciences, Imphal [the prevalence of $\mathrm{TB}$ in diabetics was $27 \%$ by radiological 
diagnosis and $6 \%$ by sputum positivity]. But the clinical symptoms and presentation of pulmonary tuberculosis was found to be similar in patients with or without diabetes.

Ref: Indian. J. of Med Res., 130 July 2009, pp 1-4.

Also similar study in Pakistan in 2006 shows similar findings with regards to symptomatology. "Though the presenting symptoms of PTB does not seem to be modified with DM, yet DM can affect the radiological findings:

1. Annals vol. 15 No. 2 APR-JUN 2009, Quazi et al. The other two studies showing no significance between symptomatology in DM and non DM-TB.

2. Kossii et al., Pulmonary tuberculosis in diabetics. Respiration.

3. Perez Guzman C et al., Ind. J of Tub. Lung Dis. Apr 2003.

In Study Group: Radiological studies showed that $48.21 \%$ had bilateral lesions, $16.07 \%$ left sided and $41.07 \%$ right sided lesions.

In Control Group: Bilateral 14.2\%, Right sided 64.28\%, and Left sided $17.85 \%$.

\section{This is in similarity with various studies like}

1. "Tuberculosis had more pronounced radiological signs." Lalit Kant., Ind. J. of Tub., No.4., Vol. 50., New Delhi., Oct.2003

2. Mboussa et al., Course of TB., Rev Pneumol clinic. 2003.

Also cavity with infiltration were seen bilaterally only DM-TB group.

No cases of bilateral cavity with infiltration was seen in Non DM-TB group.

In the study group three zones were involved in $10.7 \%$ four zones involved in $3.57 \%$, five zones were involved in $1.78 \%$.

Whereas in control group it was three zones $14.2 \%$, four zones $0 \%$, and five zones $0 \%$. This shows more number zones involved bilaterally in diabetics than controls.

\section{This was seen in other related studies like}

1. Perz Guzman et al., Mexico. 2002.,

2. Shaik MA et al., Saudi Arabia. 1994. " $48 \%$ had lower lung zones involved."

3. FA Deshmukh., et al., Bihar 1984.

4. Quazi et al., 2006 Pakistan., "In 75 X-ray films 22 cases showed multiple shadows and atypical radiological involvement with $13 \%$ middle zone involved and 58\% lower zone involved.

\section{CONCLUSION}

In the present study, the prevalence of pulmonary tuberculosis in diabetics is $11.2 . \%$ with male predominance of above 40 years age group with most patients having fever as main complaint and haemoptysis as least complaint.

It can be concluded that there is increased susceptibility of tuberculosis in diabetic smoker and sputum positivity more in diabetics than non-diabetics with more number of zones involved bilaterally in diabetics.

\section{REFERENCES}

1. Hoorens, Mbyana JC, Gan D, Allogt B, Bakker K, Brown JB, Ramachandran A, et al. IDF diabetes atlas, 2006, 3rd ed., Brusssels: chapter 1, page 5-6.
2. Ramachandran A, Snehalatha C, Vijay V. Temporal changes in prevalence of type 2 diabetes and impaired glucose tolerance in Urban Southern India. Diabetes Res Clin Pract 2002;58: 55-60.

3. King H, Aubert RE, Herman WH. Global Burden of Diabetes, 1995-2025: Prevalence, numerical estimates, and projections. Diabetes Care 1998;21:1414-31.

4. World Health Organization. India: Core Programme Clusters, Communicable Diseases and disease Surveillance, Tuberculosis. Geneva: WHO; 2009.

5. World Health Organization: Global Tuberculosis Control WHO Report. Geneva: WHO; 2009.

6. Morton $\mathrm{R}$, editor. Phthisolgia: or a treatise of consumptions. Londan: Smith and Walford; 1694.

7. Ramadoss A: TB INDIA 2009 RNTCP Status Report 'I am Stopping TB.' (Central TB Division), New Delhi: Ministry of Health and Family Welfare; 2009.

8. Ezung T, Devi NT, Singh NT, Singh TB. Pulmonary tuberculosis and diabetes mellitus- a study. J Indian Med Assoc 2002;100:378-9.

9. Patel JC. Complication in 8793 cases of diabetes mellitus 14 year study in Bombay Hospital. Indian J Med Sci 1989;43:177-83.

10. Jeon C, Murray M. Diabetes mellitus increase the risk of active tuberculosis: A systematic review of 13 observational studies. PLoS Med 2008;5:e152.53.

11. Stevenson CR, Critchley JA, Forouhi NG, Roglic G, Williams $B G$, Dye $C$, et al. Diabetes and the risk of tuberculosis: a neglected threat to public health? Chronic Illn2007;3:22845 .

12. Stevenson CR, Forouhi NG, Roglic G, Williams BG, Lauer JA, Dye $\mathrm{C}$, et al. Diabetes and tuberculosis incidence. BMC Public Health 2007;7:234.

13. Englebach K. Passagerer Diabetes Mellitus bei 2 Tuberkulosekranken. [Transitory Diabetes mellitus in two tuberculotics] J Beitr Klin Tuberk Spezif Tuberkuloseforsch 1954;110:470-3.

14. Nichols GP. Diabetes among young tuberculous patients; a review of the association of the two diseases, Am Rev Tuberc 1957;76:1016-30.

15. Mugusi F, Swai A, Alberti K, Melarty G. Increased prevalence of diabetes mellitus in patients with pulmonary tuberculosis in Tanzania. Tubercle 1990;71:271-6.

16. Singla R, Khan N, Al-Sharif N, Al-Sayegh MO, Shaikh MA, Osman MM. Influence of diabetes on manifestations and treatment outcome of pulmonary tuberculosis, Int. J Med sci. public health 2015;4(2):245-249.

17. Suarez-Garcia I, Radriguez-Blanco A, Vidal- Perez JL, Garcia-Viejo ML, Lopez OJ et al., Jaras-ernandez Mj, Lopez OJ. et al. Diabetes and Tuberculosis, a dangerous laison and no white tiger, Indian J Med.Res130, July 2009, pp1-4.

18. Balasubramania R, Ramanathan U, Thyagarajan K, Ramachandran, Rajaram K. A study of TB treatment outcome in known diabetic patient under RNTCP, Indian J of TB., 2007;54:168-76.

19. Rekha B, Balasubramanian R, Swaminathan S, Ramachandran R, et al. Tuberculosis and Diabetes mellitus - an underappreciated association. Archives of medical science, 2014 OCT 27;10(5):1019-1027. 